\title{
Educación de vanguardia: generar conocimiento científico y humanístico
}

\author{
Ana María del Pilar Martínez Hernández
}

Sin duda, marzo de 2020 será recordado durante largo tiempo. En la redacción de la RDu queremos hacer énfasis en dos de los múltiples acontecimientos que han ocurrido en este mes, los que consideramos de mayor relevancia dados el interés, la inquietud y las múltiples reflexiones que han generado en la Universidad, en nuestra sociedad y en el mundo entero, por su trascendencia para el futuro próximo de la humanidad.

El primero se relaciona con las convocatorias emitidas por un sinnúmero de organizaciones feministas para realizar una marcha el Día Internacional de la Mujer, y para que, en contraste, el día subsecuente, 9 de marzo, se realizará en México el denominado Un día sin nosotras. Cabe destacar que si bien la primera de las acciones mencionadas, la megamarcha, se ha venido realizando a lo largo de más de 45 años, desde la institucionalización de esta fecha por la Organización de las Naciones Unidas, en 1975.

Sin embargo, este año, el llamado a marchar en nuestro país, a través de la etiqueta \#8M, se contextualizó en la exigencia imperativa de las mujeres de detener la violencia de género que ha venido incrementándose en los últimos tiempos, hasta llegar a la cifra promedio, durante 2019 y enero de 2020, de diez feminicidios diarios, lo mismo mujeres que de niñas.

La convocatoria reunió, según fuentes oficiales, a 80 mil asistentes en la capital de la República, cifra que según las organizaciones convocantes fue de al menos el doble. La relevancia de este acto es que como participantes superamos las ideologías y la pertenencia a partidos políticos y marchamos generaciones diversas: abuelas, madres, hijas, hermanas y nietas; contingentes ordenados de mujeres zapatistas, familiares de las mujeres asesinadas, una enorme cantidad

DoI: http://doi.org/10.22201/codeic.16076079e.2020.v21n2.a0 
de mujeres jóvenes, amigas, amigas de amigas, vecinas y compañeras de trabajo; grupos de maestras y alumnas universitarias, de instituciones públicas y privadas; madres de familia con sus hijas e hijos pequeños, mujeres de la tercera edad y con necesidades especiales; colectivos de la comunidad LGBTTIIQ, hombres heterosexuales que apoyan las demandas, organizaciones sociales y sindicales, entre otros.

Las calles contenían una marea humana ataviada en tonos lilas, violetas y morados, salpicados de pañuelos verdes y ropa negra, de luto. Las tomas fotográficas y los videos dan cuenta de una comunidad que, bailando, cantando, gritando consignas, avanzaba emanando fuerza y alegría desbordadas, mientras que, al mismo tiempo, con rabia exigía seguridad, alto a la impunidad, justicia e igualdad. Los carteles afirmaban "No somos histéricas, somos históricas", "Mi mamá me enseñó a luchar", "Ni siquiera tendríamos que estarles pidiendo que nos respeten", además de las ya conocidas "Ni una menos" y "Nos queremos vivas".

En contraste, el día siguiente, lunes 9 de marzo, se convocó a "UnDíaSinMujeres" o "UnDíaSinNosotras". El llamado fue a realizar un paro nacional para protestar contra la violencia de género, así como para mostrar la trascendencia de nuestra participación en todos los ámbitos de la vida social: en el trabajo, la escuela, los servicios públicos y de salud, la vida económica y también en la doméstica. Se convocó a la ausencia, el silencio, la invisibilización, para hacer notar que somos imprecindibles en lo que hacemos, en lo que aportamos de manera cotidiana a la vida social. Emulando la huelga simbólica que las mujeres de Islandia realizaron el 24 de octubre de 1975, el grupo feminista Brujas del Mar, del estado de Veracruz, hizo la propuesta y la aceptación fue total.

Las calles lucieron vacías, al igual que el transporte público, donde para sorpresa de todos, los vagones o secciones destinadas a las mujeres fueron respetados. Se cancelaron actividades en escuelas, los comercios lucieron desiertos, en la mayoría de ellos no hubo compras ni vendedoras que atendieran a los clientes. Aunque también es cierto que muchas mujeres tuvieron que acudir a sus centros de trabajo porque les descontarían un día de salario o bajarían sus comisiones por ventas, o debido a que tienen sus propias microempresas, entre otras razones.

Las repercusiones económicas directas al piB se calculan en más de 35 mil millones de pesos, aunque se pudo haber alcanzado hasta 43.5 mil millones de pesos del valor agregado total a la economía de un día. Como dijo la sección Rayuela que apareció al día siguiente en el periódico La Jornada: "Fue un 9 de marzo inolvidable. Nunca una ausencia hizo tanto ruido".

El segundo acontecimiento a destacar, que empezó mucho antes del mes de marzo, se extenderá más allá del de abril, y que se encuentra en su nivel máximo a nivel mundial, se refiere al brote epidémico provocado por una nueva especie de coronavirus, que produce la enfermedad que la Organización Mundial de la Salud (oms) ha denominado covid-19. 
Los primeros casos del brote se detectaron en la ciudad de Wuhan, capital de la provincia de Hubei, en la zona central de la República Popular China, en la confluencia de los ríos Yangtsé y Han. Es una ciudad de importancia histórica - data de más de 3,500 años-, política, financiera, económica, comercial, cultural y educativa, con una población de aproximadamente 11 millones de habitantes.

La enfermedad inició entre noviembre y diciembre del 2019; sin embargo, la oms declaró que representaba una amenaza global hasta el 30 de enero de 2020 (BBC, 2020; World Health Organization [WHo], 2020b), y hasta el momento confirmó la existencia de más de 191,127 personas contagiadas y 7,807 fallecidos (wHO, 2020a).

Sorprende el nivel de propagación de esta enfermedad que pasó de ser caracterizada como epidemia, en tanto el foco se localizaba sólo en China, al nivel de pandemia, dada la transmisión sostenida, eficaz y continua de esta enfermedad que afecta ya al mundo entero.

El contagio a otras regiones se dio inicialmente por importación, es decir, debido a personas infectadas de manera directa en Wuhan, que actuaron como portadoras del virus. Después, la transmisión de esta enfermedad ocurrió de estos sujetos a la población de los países a los que llegaron, iniciándose la fase de transmisión comunitaria, que se encuentra en expansión en los diversos países y continentes, ya que la característica de este virus es su alta transmisibilidad.

En apenas unas semanas, los casos de covid-19 se han multiplicado fuera de China, así como el número de países afectados. La oms estima, de manera preliminar, que la tasa de contagio del virus $\left(\mathrm{R}^{0}\right)$, sin ningún tipo de intervención, es de 1.4 a 2.5 (WHO, 2020b), es decir, que cada persona infectada puede a su vez infectar a entre 1.4 y 2.5 personas, por lo que resulta difícil de controlar. Se pide a los gobiernos que tomen medidas urgentes, agresivas y sistemáticas para evitar que las cifras de contagio y defunciones sigan incrementándose de manera alarmante.

En el caso de México, se ha dado seguimiento a esta pandemia. Nuestro país posee un largo historial para lidiar con epidemias que nos han afectado y se encuentran documentadas desde la época prehispánica. Nos encontramos a la espera de que se tomen medidas radicales para evitar el contagio comunitario masiva e irreversiblemente.

Por lo pronto, la UnAm ha implementado una política de distanciamiento y confinación de su población estudiantil y docente, dando la opción del trabajo a distancia para evitar una repercusión mayor a la inevitable expansión de la pandemia. Aislamiento. Habrá que actuar con absoluta responsabilidad y de manera prudente e informada para contribuir desde nuestro ámbito de actuación y evitar escenarios más críticos al que ya vivimos. 
El equipo que edita la RDU se encuentra en proceso de integrar información acerca de los dos acontecimientos mencionados. En este número estamos estableciendo una serie de ligas de información para informarnos sobre la pandemia. Y, próximamente se publicará un número especial sobre el tema de Género y lo que se está haciendo al respecto.

Mientras tanto, les invitamos a leer el conjunto de materiales que nos han enviado y que hemos seleccionado para el segundo número -marzo-abrilde este año. En ellos encontrarás una variedad de temas que seguramente generarán tu interés y que te aportarán nuevos conocimientos sobre diversos campos, que describimos a continuación.

Como siempre, en el apartado Varietas se abordan una serie de temas científicos de diversas áreas del conocimiento:

Al hielo comúnmente lo asociamos con los cubitos que nadan en una bebida, una pista de patinaje e incluso para disminuir los moretones, pero es mucho más que eso. Muchas historias se encuentran congeladas en los hielos terrestres y en el artículo "Historias congeladas en el hielo polar", Guillermo N. Murray-Tortarolo nos llevará a las partículas de plomo atrapadas en el Polo Norte y nos hablará de cómo éstas reconstruyen la historia de nuestra humanidad. Después, viajaremos al espacio y nos contará la manera en que el berilio congelado nos ayuda a entender la historia de nuestro Sol. Finalmente, conoceremos el riesgo que el cambio climático implica para este recurso histórico y la memoria que podríamos perder si el hielo polar se derrite.

¿Has visto un insecto obeso? ¿Existe tal cosa? Es evidente que en humanos y animales domésticos la obesidad representa un serio problema, pero ¿qué hay de los animales silvestres? ¿Padecen obesidad? Daniel González-Tokman te invita a ahondar en el tema de la obesidad en insectos y a descubrir los mecanismos y procesos que intervienen en este fenómeno en su artículo "La obesidad, un raro padecimiento en los insectos".

Antes de que puedan crecer nuevas plantas, las semillas deben abandonar la vaina. Pero ¿qué pasaría si todas las semillas producidas por una planta cayeran justo debajo de la planta madre? Las plantas nuevas estarían demasiado apretadas y la planta grande podría no dejarles suficiente luz o agua para que todas se desarrollen adecuadamente. Por lo anterior, es necesario que las semillas viajen más allá, este proceso se llama dispersión. En el artículo "Los aliados emplumados de los Copales y Cuajiotes de México: aves y la dispersión de semillas de Bursera", Carlos A. Cultid-Medina y Yessica Rico nos hablan de la relación entre las aves y la burseras, en el proceso de la dispersión de semillas.

La producción de larvas de peces marinos, también llamada larvicultura, con fines de cría en estanques, ¿es rentable? En el artículo "¿Cultivo de peces marinos? Hablemos de Larvicultura en estanques", Sergio Escárcega Rodríguez 
nos habla de esta práctica milenaria que consiste en cultivar organismos acuáticos como moluscos, peces, algas y pulpos, entre otros, para aumentar su producción. También nos pone al tanto de la situación actual de esta actividad en México y nos cuenta de un modelo de producción alternativo que abre la posibilidad de manejar enormes cantidades de larvas con mayores márgenes de sobrevivencia.

Muy probablemente has escuchado acerca de las medusas y de los corales. Éstos pertenecen al grupo de organismos acuáticos y venenosos, de cuerpo gelatinoso y con tentáculos, denominado cnidarios. En el artículo "Anémonas, corales y medusas: Ios cnidarios y su importancia médica", Fernando Lazcano Pérez, Zayil Salazar Campos y Humberto González-Márquez nos brindan un recuento de las características de estos seres, su forma de vida y de la importancia que tienen para la farmacología.

En teoría, los enjuagues bucales ayudarían a eliminar las bacterias, pero su mal uso puede tener efectos adversos. En "Antisépticos orales, ¿los estamos utilizando de manera correcta?", Saray Aranda Romo, Juan Manuel Mendoza Méndez, Juan Antonio Cepeda Bravo y Othoniel Hugo Aragón Martínez tratan la salud bucal, los tipos de enjuagues existentes, su funcionamiento y los riesgos que conllevan, debido a que alteran la microbiota oral.

La adolescencia es una etapa complicada por los diversos cambios que en ella ocurren. Así, implica desafíos en el tema de la sexualidad, en parte debido a la falta de educación sexual en nuestra sociedad. En "Más allá de pajaritos y abejitas: sexualidad en el adolescente mexicano", Claudia Alejandra Cervantes Lara, Alicia Álvarez Aguirre y María Mercedes Moreno Gónzalez tocan cuestiones como el embarazo adolescente y enfermedades de transmisión sexual y, además, presentan estrategias para alcanzar una sexualidad libre, informada y responsable.

Hay materias que son complicadas de entender. Pero ¿qué sucede cuando uno no es el problema? Irma Sofía Salinas Hernández aborda algunos resultados de estudios sobre el aprendizaje a nivel preparatoria y pone en evidencia que temas como la fotosíntesis y la respiración celular requieren habilidades cognitivas que aún no se han desarrollado entre los 12 y 16 años. De esta manera, nos da la respuesta de "¿Cómo sobrevivir a la enseñanza del metabolismo celular en bachillerato?" en la sección Continuum educativo.

En la sección Universidades se habla de una plataforma digital que da acceso a diversos recursos y productos sobre innovación educativa, ¿lo imaginas? Pues la Coordinación de Desarrollo Educativo e Innovación Curricular (CODEIC) desarrolló el Repositorio de Innovación Educativa, un espacio dinámico de consulta, participación y discusión que facilita la sistematización y visibilización de las innovaciones educativas que se realizan en la unAm. Roberto Santos Solórzano y Patricia González-Flores nos platican más de esta plataforma en el artículo "Innovar en compañía: el Repositorio de Innovación Educativa de la unAm". 
Por último, no olvides visitar la sección Caleidoscopio y leer el artículo "Más que humanos: el robot en la ciencia ficción", donde Mario César Arizmendi Guzmán nos propone una reflexión acerca de lo que significa el ser humano, a través de varias obras representativas de la literatura. ¿Quién es el verdadero autómata, aquel que en la ciencia ficción es capaz de crear y sentir? ¿O nosotros, cada vez más alienados, mecánicos e insensibles?

Esperamos, una vez más, cumplir con la misión de la RDu al hacer llegar a nuestros lectores y nuestras lectoras conocimiento científico, humanístico y educativo de vanguardia.

\section{Referencias}

* BBC. (31 de enero de 2020). Coronavirus declared global health emergency by wно. Recuperado de: https://www.bbc.com/news/world-51318246?fbclid=IwAR05RaV x4jyjsHiWRyGUBmHrVM4rb1LtE7MZOs YkvEFTPHGNxpHjPoGnEE.

* Rayuela. (10 de marzo de 2020). La Jornada, contraportada.

* World Health Organization (wHo). (18 de marzo de 2020a). Coronavirus disease 2019 (covID-19) Situation Report - 58. Recuperado de: https://www.who.int/docs/ default-source/coronaviruse/situation-reports/20200318-sitrep-58-covid-19. pdf?sfvrsn=20876712 2 .

* World Health Organization (wHO). (30 de enero de 2020b). Statement on the second meeting of the International Health Regulations (2005) Emergency Committee regarding the outbreak of novel coronavirus (2019-nCoV). Recuperado de: https://www.who. int/news-room/detail/30-01-2020-statement-on-the-second-meeting-of-theinternational-health-regulations-(2005)-emergency-committee-regarding-theoutbreak-of-novel-coronavirus-(2019-ncov).

\section{Cómo citar este artículo}

* Martínez Hernández, Ana María del Pilar (2020). Educación de vanguardia: generar conocimiento científico y humanístico. Revista Digital Universitaria (RDU). Vol. 21, núm. 2 marzo-abril. Dol: http://doi.org/10.22201/codeic.16076079e.2020. v21n2.a0. 